“@ 2018 IEEE. Personal use of this material is permitted. Permission from IEEE must be obtained for all other uses, in any current or future media, including reprinting/republishing this material for advertising or promotional purposes, creating new collective works, for resale or redistribution to servers or lists, or reuse of any copyrighted component of this work in other works." 


\title{
Minimisation of Residential Energy Cost Considering Energy Storage System and EV with Driving Usage Probabilities
}

\author{
Yanyi Sun ${ }^{1}$, Hong Yue ${ }^{1}$, Senior Member, IEEE, Jiangfeng Zhang ${ }^{2}$, Campbell Booth ${ }^{1}$
}

\begin{abstract}
Electric vehicle (EV) can be applied to discharge power back to the grid, which is called vehicle-to-grid (V2G) technology. There is a constant debate on whether V2G is an economically viable option due to the high battery degradation cost. In this work, the cost benefit of EV customers participating in V2G has been studied using different feed-in tariffs (FITs). A model is developed for minimisation of energy cost for residential users, which includes an EV, a separate energy storage system (ESS) and renewable energy supply. Key factors such as the EV driving usage, the degradation cost of EV and ESS batteries are considered. The EV driving usage is established through a designed survey, from which the probability of vehicle parking and plug in at home, the probabilities of $\mathrm{EV}$ under driving and parking outside can be calculated. Comprehensive case studies have been undertaken to investigate the optimisation strategies under various scenarios. Two types of electricity tariffs, time-ofuse (TOU) and fixed tariffs, are considered. It is revealed that certain threshold levels of FITs are expected to allow users benefit from V2G technology. Compared with non-optimised operation, the cost saving with the optimised strategy is evident in the case studies.
\end{abstract}

Index Terms - Electric vehicle (EV), vehicle to grid (V2G), energy storage system (ESS), battery degradation, driving usage, photovoltaic (PV), energy cost optimisation

\section{INTRODUCTION}

\section{A. Background}

$\underline{1}$ lectric vehicles (EVs) have become popular in the past decade, one benefit of which is to reduce greenhouse gas emission in transportation systems. The charging load of EV supplied from renewable energy resources can further reduce transportation emission [1]. A reduction in greenhouse gas emissions of $47 \% \sim 78 \%$ is reported through the photovoltaic (PV) powered EV technology [2], where the PV power feed-in rate and the interest rate can be used in policy making tools to develop low carbon transportation systems. In recent research development, minimisation of $\mathrm{EV}$ charging cost including vehicle-to-grid (V2G) has been widely investigated. It can help to alleviate the peak demands of power and minimise the energy cost of users. With V2G, an EV can be used as an energy storage device that is able to inject the stored electric power back to the grid. This can be applied as a new type of energy source and utilised together with energy storage system

\footnotetext{
The authors are with the Department of Electronic and Electrical Engineering, University of Strathclyde, Glasgow, UK (email: yanyi.sun@strath.ac.uk;hong.yue@ strath.ac.uk;campbell.booth@strath.ac.uk)
}

(ESS) to achieve optimal operation of power systems [3]. In addition, renewable energy, such as wind and solar energy, can be scheduled with EV charging so as to compensate for the uncertainty of renewable generation and reduce the cost [4-7].

When considering $\mathrm{V} 2 \mathrm{G}$ control in optimal charging strategies of EV, several benefits can be achieved according to recent studies. It can provide frequency regulation and simultaneous scheduling of the EV charging, which can suppress frequency fluctuation and reduce the additional ESS capacity requirement. The grid load profiles can be smoothed, the operation efficiency and the security of the grid can be improved [8-11]. It is reported in [12-14] that V2G can support the grid to shave the peak demand and reduce grid operational costs under proper energy policy strategies, and can also help to compensate for the uncertain wind and PV power generation.

$\mathrm{V} 2 \mathrm{G}$ techniques provide wider options for control and optimisation of EV systems, however, V2G operation increases cost of battery degradation, which needs to be considered in its applications [15]. Another issue to consider is whether the EV owners would be willing to participate in a V2G program. The economic viability of $\mathrm{V} 2 \mathrm{G}$ is unclear to $\mathrm{EV}$ owners. This is often related to factors such as battery degradation, expensive battery pack and low feed-in tariff (FIT). It is discussed in [16] that a V2G service may lead to a reduced life-cycle of an EV. The power aggregators should operate either on pay-as-you-go basis or provide consumers with advanced cash payment in order to attract more EV owners participating in V2G. The guaranteed rate of return for $\mathrm{V} 2 \mathrm{G}$ may not be sufficient to induce widespread V2G participation due to the cost in grid connection, purchase of electricity and battery degradation [17]. The EV's battery pack will need to be replaced more frequently with V2G operation [18]. The battery aging cost induced by V2G may exceed the benefit brought from V2G, and substantial subsidies are required to trigger $\mathrm{V} 2 \mathrm{G}$ service [19]. It is important for residential home EV users to consider whether V2G is economically beneficial in reducing their overall energy costs.

Some recent studies for minimising the cost of residential energy systems have included $\mathrm{V} 2 \mathrm{G}$. Cao et al. present an optimal scheduling of EV charging and V2G at household level, which takes into account the cost of battery degradation and price uncertainty [3]. Although the significance of the battery degradation has been revealed, quantitative explanations of the

\footnotetext{
2 The author is with School of Electrical, Mechanical and Mechatronic Systems, University of Technology Sydney, Sydney, Australia (email: jiangfeng.zhang@uts.edu.au)
} 
charging cost reduction and probability of vehicle usage are lacking. Another cost minimisation model proposed in [20] comprises both $\mathrm{V} 2 \mathrm{G}$ integration and the demand response strategies, from which up to $58 \%$ cost reduction can be achieved. However, the battery degradation cost, a major factor affecting the charging scheduling, is not considered in [20]. The model built in [21] is used to minimise the total charging cost by considering the battery degradation cost with V2G. It shows that the reward value under the assumed FIT can cover the degradation cost, and could encourage $\mathrm{EV}$ owners to participate in V2G program. However, the minimum assumed FIT value in [21], USD $0.2 / \mathrm{kWh}$, is still high compared with the practical value, and it is much larger than the electricity price used in the case studies. According to UK government's report, the total FIT is around $£ 0.08 / \mathrm{kWh}$, and the electricity price is around $£ 0.16 / \mathrm{kWh}$. It is obvious that electricity price is much higher than the existing FIT. Whether V2G will benefit the EV owner is still questionable. In [22], an optimisation model is built up for residential household including V2G application, battery degradation, renewable generation and other loads, in order to minimise the daily energy cost. Daily cost savings obtained from the optimised case can be achieved up to $15.5 \%$, and the remaining state of charge (SOC) of the EV can be guaranteed to stay not less than $49.5 \%$. A method is presented in [23] to minimise the electricity expenditure by scheduling charging and discharging of EV's battery. The total bill reduction is higher when more EVs are involved and batteries of larger capacities are used. It is argued in [24] that lead-acid and NiMH batteries are not cost effective in V2G while lithium-ion batteries are more acceptable in UK. The lithium-ion battery price used in [24], £128/kWh, is much lower than the replacement cost of EV battery. Therefore, the latest EV models need to be applied to reassess the benefits of V2G. One factor that has been largely ignored in most studies is the EV customers' driving usage such as driving time, parking time, and daily driving distance, which would certainly influence the charging and discharging of EVs and the cost accordingly [25].

\section{B. Contributions}

In this work, we will focus on minimisation of residential household energy cost by considering EV with driving usage, EV and ESS battery degradation, and PV energy supply. The novel development will be made in the following aspects.

1. Develop a model for minimisation of the energy cost of a residential household with an EV, an ESS, and other residential loads, where the EV's usage patterns are described by probability levels. Optimisation results based on this model can be used to determine whether $\mathrm{V} 2 \mathrm{G}$ is beneficial for the EV owners under the optimal charging and discharging strategy.

2. Design a practical survey of EV daily usage including driving purposes and usage at different time periods. Information such as the driving distance, starting time and duration when the vehicle is away from home, time duration for parking outside, etc. will be collected and processed to calculate driving usage probabilities.

3. Investigate the total cost saving through case studies for various scenarios under fixed and time of use (TOU) tariffs.
The remaining part of the paper is organised as follows. The optimisation problem of the residential household EV user's energy cost, including multiple factors, is formulated in Section II. Case studies and results under different scenarios using two typical FITs have been extensively discussed in Section III. Finally, conclusions and discussions are made in Section IV.

\section{END USER COST MODEL FOR OPTIMISATION}

\section{A. Residential Household Energy System}

The residential household energy system under study is illustrated in Fig. 1, where the components include a PV power system, an EV, an ESS, other residential loads and the power grid. Here $P_{1}\left(P_{1}>0\right)$ is the output power of the PV system, $P_{2}$ is the EV charging or discharging power, and $P_{3}$ is the input/output power of the ESS. Other loads of the residential home is represented by $P_{4}\left(P_{4}<0\right)$. The home system is connected to the grid. The input and output power to and from the grid is represented by $P_{5}$.

In Fig.1, an arrow pointing towards a block is defined as the positive direction indicating that the power $P_{j}$ flows into the block. The total operational cost of the energy system is considered over a 24 hours' time period with the uniform sampling period of 1 hour. In this case, there are 24 time periods or slots, each being denoted by index $i(i=1,2, \cdots, 24)$. The initial time period is assumed to start from 8:00 am with $i=1$. The units for power flows are in $\mathrm{kW}$. The following power balance holds for the system for all time slots.

$$
\sum_{j=1}^{5} P_{j}(i)=0 \quad(i=1,2, \mathrm{~L}, 24)
$$

It should be noted that $P_{2}(i)$ and $P_{3}(i)$ are the two variables that can be controlled through optimisation. $P_{1}(i)$ and $P_{4}(i)$ are given information, and $P_{5}(i)$ can be calculated from (1) when all the other four powers are available.

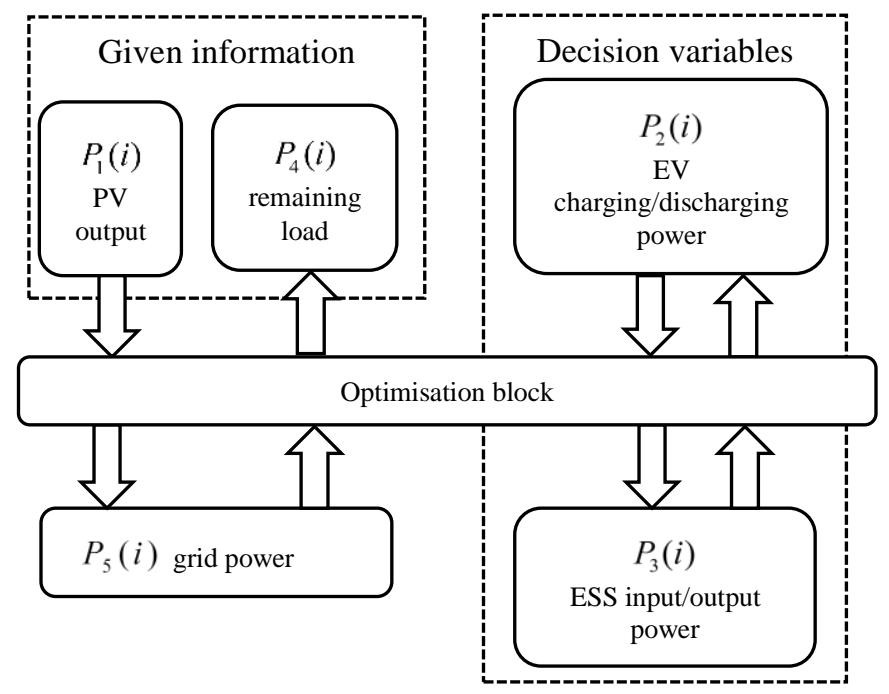

Fig. 1 Schematic of the grid connected residential household system

The purpose of design is to minimise the total operational cost of the energy system over a 24 hours' time period, so that the user's profit is maximised. The cost function, $C_{\text {total }}$, includes the following parts: the cost to purchase electricity from the grid $\left(C_{\text {purchase }}\right)$, the degradation cost of the EV battery 
$\left(C_{E V}\right)$ due to charging/discharging at home, the degradation cost of EV battery due to driving outside $\left(C_{E V \text {-outside }}\right)$, the cost of the ESS battery $\left(C_{E S S}\right)$, and also the income from selling electricity to the grid which is denoted by $\left(C_{\text {income }}\right)$ and is deducted from the total cost.

$$
C_{\text {total }}=C_{\text {purchase }}+C_{E V}+C_{E S S}+C_{E V \text {-outside }}-C_{\text {income }}
$$

A flow diagram of the optimisation model has been shown in Fig. 2.

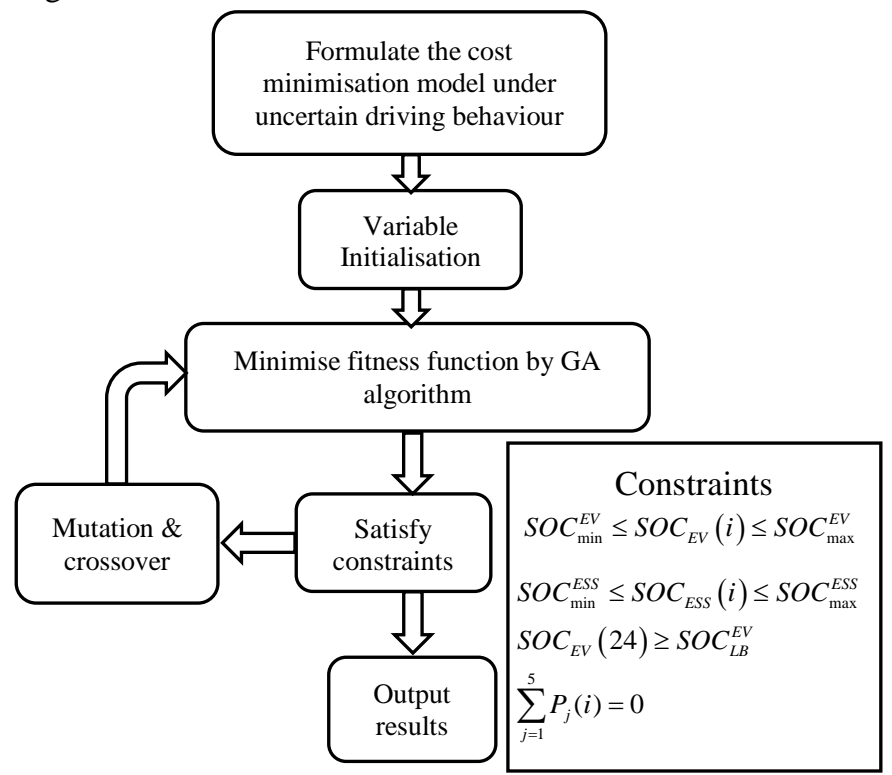

Fig. 2 A flow diagram of the optimisation model

The PV output power is sourced from [26], which is shown in (3). The EV charging/discharging power and the power corresponding to ESS on-off status can be described as follows.

$$
\begin{aligned}
P_{1}(i) & =\lambda \cdot S(i) \cdot A \\
P_{2}(i) & = \begin{cases}+a \cdot \tau, & \text { if EV is discharging } \\
-a, & \text { if EV is charging } \\
0, & \text { otherwise }\end{cases} \\
P_{3}(i) & = \begin{cases}+a \cdot \tau, & \text { if ESS is discharging } \\
-a, & \text { if ESS is charging } \\
0, & \text { otherwise }\end{cases}
\end{aligned}
$$

Here $S(i)$ is the solar irradiance $\left(\mathrm{kW} / \mathrm{m}^{2}\right) ; \lambda(0<\lambda<1)$ is the solar irradiance to electricity conversion efficiency which is selected as $15 \%$ in this paper; $A$ is the solar panel area $\left(\mathrm{m}^{2}\right)$; $a(\mathrm{~kW})$ is a positive real number used for both EV and ESS; $\tau$ is the discharging efficiency accounting for the energy conversion loss, which is selected as $90 \%$ according to [27]. An intermediate term $\beta_{2}^{\circ}$ is used in (4) to represent EV charging and discharging power when the vehicle is parking at home. Equations (4) and (5) describe the EV and ESS charging/ discharging status, which are the variables to be optimized.

\section{B. EV Driving Usage Probabilities and Daily Power Use}

In order to characterise the uncertain nature of car usage, a practical survey of EV daily usage is designed. The survey includes different driving purposes and usage time periods. Information such as the driving distance, starting time and duration when the vehicle is away from home, time duration for parking outside, has been collected. Those power variations due to the change of driving behaviours, such as acceleration, deceleration, and speed control, are not considered in this work. Then the raw data is processed and used to calculate the following probabilities.

$p_{k 1}(i)$ : the probability of EV parking and plugging in at home within time slot $i$;

$p_{k 2}(i)$ : the probability that the $\mathrm{EV}$ is under driving within time slot $i$; and

$p_{k 3}(i)$ : the probability that the EV is parking outside within time slot $i$.

The sum of these probabilities should be equal to 1 since they represent all the possible scenarios, i.e.

$$
p_{k 1}(i)+p_{k 2}(i)+p_{k 3}(i)=1
$$

When an EV is parking outside, it is assumed to be disconnected from the grid; therefore, no charging or discharging activities take place, and the term $p_{k 3}(i)$ can be ignored for this situation. The power flow from EV to the control block depends on whether the battery is under charging or discharging status. Considering the above EV driving usage probabilities, the average EV power, i.e. the mathematical expectation of the EV power, can be calculated as follows:

$$
P_{2}(i)=\beta_{2}(i) \cdot p_{k 1}(i)-\frac{Q_{E V}}{T} \cdot p_{k 2}(i) \cdot \sum_{l=1}^{N_{d}} \frac{d(l) p_{l}}{d_{\text {total }}}
$$

where $d_{\text {total }}$ is the total distance $(\mathrm{km})$ the EV can drive with a fully charged battery; $Q_{E V}$ is the EV battery capacity $(\mathrm{kWh})$. The total number of driving periods is represented by $N_{d} ; d(l)$ is the $l$-th possible driving distance; $p_{l}$ is the probability corresponding to $d(l)\left(l=1, \cdots, N_{d}\right) ; T$ is the period length, which is 1 hour in this work.

As can be seen from (7), the term of mathematical expectation of driving power consumption is included. The daily use of a vehicle contains many uncertainties for various reasons. When the EV's owner plugs out the vehicle from the charging slot leaving home, the remaining SOC of the EV will be different from that when it is plugged back to the slot after the driving. The application of $\mathrm{V} 2 \mathrm{G}$ technology will be influenced when considering these variations. In this study, these variations have been analysed from a real questionnaire (see Appendix A), in which the data has been transformed to the corresponding probabilities (see Appendix B). Then, the mathematical expectation of the driving power consumption within each time slot is calculated.

\section{Battery Degradation Cost for EV and ESS}

According to [28], battery degradation cost consists of three parts: temperature related degradation, SOC related degradation, and the depth of discharge (DOD) related degradation. The temperature related degradation is caused by the fluctuations in charging power or discharging power. It is negligible for the EV parking at home and for the ESS since their charging/discharging current and voltage are usually stable, thus the charging power are close to their minimum levels. Only the SOC related degradation and the DOD related degradation are considered.

The hourly cost of SOC related degradation can be represented as follows [28]: 


$$
C_{S O C}(i)=C_{0} \cdot \frac{\alpha \cdot S O C(i)-\beta}{C F_{\max } \cdot 15 \cdot 365 \cdot 24},
$$

where $C_{0}$ is the battery purchase price, $\operatorname{SOC}(i)$ is the value of SOC within the $i$-th period. The parameters, $\alpha$ and $\beta$, are determined by linear regression from the measured data, which are calculated to be $1.59 \cdot 10^{-5}$ and $6.41 \cdot 10^{-6}$, respectively [29]; $C F_{\max }$ is the maximum capacity fade constant which is assumed to be $20 \%$. In this paper, the battery life time is assumed to be 15 years as sourced from [29].

The relationship between the charging/discharging power, $P$, and the $\mathrm{SOC}$ can be determined as $S O C=S O C_{I N}-P / Q$ [30], where $S O C_{I N}$ is the initial value for the SOC, $Q$ is the battery capacity. Since the driving probabilities will be considered, the EV's SOC can be derived from [30] as:

$$
\operatorname{SOC}_{E V}(i)=S O C_{I N}^{E V}-\frac{1}{Q_{E V}} \sum_{\rho=1}^{i} P_{2}(\rho)
$$

From (8) and (9), the SOC related degradation daily cost of the EV parking at home within the $i$-th time period is represented as follows:

$$
C_{S O C}^{E V}(i)=\frac{C_{0}^{E V} \cdot\left(\alpha \cdot\left(S O C_{I N}^{E V}-\frac{1}{Q_{E V}} \sum_{\rho=1}^{i} P_{2}(\rho)\right)-\beta\right)}{C F_{\text {max }} \cdot 15 \cdot 365 \cdot 24}
$$

The DOD related degradation cost per discharging cycle (£/cycle) can be expressed by $C_{0} \cdot\left(\Delta L_{D O D} / N_{\text {total }}\right)$ where $\triangle L_{D O D}$ is the DOD of a particular discharging cycle that can be obtained from $P_{\text {Discharge }} / Q_{E V}$, where $P_{\text {Discharge }}$ is the discharging power. $N_{\text {total }}$ is the total number of discharging cycles corresponding to $\Delta L_{D O D}[28,31]$. In this study, the polynomial function between $N_{\text {total }}$ and $\Delta L_{D O D}$ is obtained through curve fitting using data from [31]:

$$
\begin{aligned}
& N_{\text {total }}=f\left(\Delta L_{D O D}\right)= \\
& \left(\begin{array}{l}
1.06 \cdot\left(\Delta L_{D O D}\right)^{4}-2.80 \cdot\left(\Delta L_{D O D}\right)^{3} \\
+2.66 \cdot\left(\Delta L_{D O D}\right)^{2}-1.07 \cdot\left(\Delta L_{D O D}\right)+0.17
\end{array}\right) \cdot 10^{5}
\end{aligned}
$$

Hence, the DOD degradation cost per discharging cycle can be written as $C_{0} \cdot\left(\Delta L_{D O D} / f\left(\Delta L_{D O D}\right)\right)$. Assume that there are $n_{1}$ discharging cycles during the day, with each of them corresponding to a DOD degradation cost, then the DOD related degradation daily cost is represented as follows:

$$
C_{D O D}=C_{0} \cdot \sum_{m=1}^{n_{1}} \frac{\Delta L_{D O D, m}}{f\left(\Delta L_{D O D, m}\right)}
$$

Following (12), the DOD related degradation cost of EV parking at home within time period $i$, denoted by $C_{D O D}^{E V}(i)$, can be written as

$$
C_{D O D}^{E V}(i)=\sum_{m=1}^{n_{1}} \frac{\Delta L_{D O D, m}}{f\left(\Delta L_{D O D, m}\right)} C_{0}^{E V} \cdot p_{k 1}(i)
$$

Similarly for ESS, the SOC related degradation cost and the DOD related degradation cost within the $i$-th time period, denoted by $C_{S O C}^{E S S}(i)$ and $C_{D O D}^{E S S}(i)$, respectively, are written as follows:

$$
\begin{gathered}
C_{S O C}^{E S S}(i)=\frac{C_{0}^{E S S}\left(\alpha \cdot\left(S O C_{I N}^{E S S}-\frac{1}{Q_{E S S}} \sum_{\rho=1}^{i} P_{3}(\rho)\right)-\beta\right)}{C F_{\max } \cdot 15 \cdot 365 \cdot 24} \\
C_{D O D}^{E S S}(i)=\sum_{m=1}^{n_{1}} \frac{\Delta L_{D O D, m}}{f\left(\Delta L_{D O D, m}\right)} C_{0}^{E S S}
\end{gathered}
$$

where $Q_{E S S}$ is the ESS battery capacity.

The overall battery degradation cost of EV and ESS over 24 hours is the sum of the degradation costs from SOC and DOD for both EV and ESS at each hour, thus

$$
C_{E V}+C_{E S S}=\sum_{i=1}^{24}\left(C_{S O C}^{E V}(i)+C_{D O D}^{E V}(i)+C_{S O C}^{E S S}(i)+C_{D O D}^{E S S}(i)\right)
$$

\section{Purchasing Cost and Selling Income}

The total electricity purchasing cost, $C_{\text {purchase }}$, is determined by $P_{5}(i)$ only, where $P_{5}=-\sum_{j=1}^{4} P_{j}$, therefore

$$
C_{\text {purchase }}=\sum_{i=1}^{24} P_{5}(i) \cdot \operatorname{sgn}\left(P_{5}(i)\right) \cdot \mu(i)
$$

where $\mu(i)$ is the unit electricity price, and the sign function $\operatorname{sgn}(\cdot)$ is defined as follows.

$$
\operatorname{sgn}(x)= \begin{cases}1, & \text { if } x \geq 0 \\ 0, & \text { otherwise }\end{cases}
$$

Here only the positive values of $P_{5}(i)$ are considered in the purchasing cost.

According to [32], the FIT value, consists of two parts, the generation tariff, $v_{\text {generation }}(i)$, and the export tariff, $v_{\text {export }}(i)$. The generation tariff is a fixed payment from the electricity supplier for every $\mathrm{kWh}$ the renewable system generates, such as PV in this work. The export tariff is the unit payment for every kWh the system exports the electricity power back to the electricity supplier. Therefore, the income, $C_{\text {income }}$, from selling electricity to the grid is determined by the negative values of $P_{5}(i)$ and the total electricity generation from PV system, and it can be written as follows:

$$
\begin{aligned}
C_{\text {income }} & =\sum_{i=1}^{24} P_{5}(i) \cdot\left(\operatorname{sgn}\left(P_{5}(i)\right)-1\right) \cdot v_{\text {export }}(i) \\
& +\sum_{i=1}^{24} P_{1}(i) \cdot v_{\text {generation }}(i)
\end{aligned}
$$

\section{E. Overall Energy Cost Function for Optimisation}

Substituting (16), (17) and (19) into (2) will give the total cost over the control period.

$$
\begin{aligned}
C_{\text {total }}= & \sum_{i=1}^{24}\left[C_{S O C}^{E V}(i)+C_{D O D}^{E V}(i)+C_{S O C}^{E S S}(i)+C_{D O D}^{E S S}(i)\right] \\
& +C_{\text {purchase }}+C_{E V \text {-outside }}-C_{\text {income }}
\end{aligned}
$$

In order to calculate the degradation costs due to EV driving outside home, we assume that the average daily battery degradation cost, $C_{E V \text {-average }}$, is the total daily degradation cost, which can be calculated by the following equation (see [28]).

$$
C_{E V-\text { average }}=C_{0} \cdot \frac{C F_{\max }}{15 \cdot 365}
$$


According to probability analysis, $C_{E V-o u t s i d e}$ can be calculated as follows

$$
C_{E V \text {-outside }}=C_{E V \text {-average }} \cdot\left(1-\prod_{i=1}^{24}\left(1-p_{k 2}(i)\right)\right)
$$

where $1-\left(\prod_{i=1}^{24}\left(1-p_{k 2}(i)\right)\right)$ is the probability of using vehicle outside home during the day.

The cost within each time period is a function of $P_{2}$ and $P_{3}$. The displayed SOC in an EV's panel is from $0 \%$ to $100 \%$, which corresponds to the allowed driving distance ranging from 0 to the maximum. In this study, the following two constraints are necessary to restrict the displayed SOC for EV and ESS within allowed ranges.

$$
\begin{aligned}
& S O C_{\min }^{E V} \leq S O C_{E V \text {-display }}(i) \leq S O C_{\text {max }}^{E V} \\
& S O C_{\min }^{E S S} \leq S O C_{E S S \text {-display }}(i) \leq S O C_{\max }^{E S S}
\end{aligned}
$$

In addition, when the EV is plugged in for charging at home, the SOC value at the end of the control period, i.e., at $i=24$, needs to be larger than the required SOC for the next driving. This constraint is termed as the minimal terminal SOC constraint and is given as follows:

$$
S O C_{E V-\text { dispaly }}(24) \geq \frac{d_{\text {exp }}}{d_{\text {total }}} \cdot 100=S O C_{L B}^{E V}
$$

where $d_{\text {exp }}$ is the expected driving distance over the next driving period. The ratio of $d_{\text {exp }} / d_{\text {total }}$ represents the required SOC for the next driving period, which is defined as the lower bound of the terminal $S O C$, denoted as $S O C_{L B}^{E V}$. The displayed SOC is considered to be the same as the EV's SOC.

Taking all the above constraints into account, the following optimisation problem is formulated to minimise the mathematical expectation of the total operating cost of the energy system.

$$
\begin{gathered}
\min C_{\text {total }}\left(P_{2}(i), P_{3}(i)\right) \\
\text { subject to: } S O C_{\min }^{E V} \leq S O C_{E V}(i) \leq S O C_{\max }^{E V} \\
S O C_{\min }^{E S S} \leq S O C_{E S S}(i) \leq S O C_{\max }^{E S S} \\
S O C_{E V}(24) \geq S O C_{L B}^{E V} \\
\sum_{j=1}^{5} P_{j}(i)=0
\end{gathered}
$$

This is a non-convex optimisation that requires a global solution. Genetic Algorithm (GA) is a type of evolutionary algorithm that is inspired by the process of evolution in human and animal life. The GA for an optimisation problem is based on binary coded genetics, which means an optimisation function will be encoded as arrays of bit strings to represent chromosomes, and the fitness selection, mutation and crossover procedures can be applied to find the optimal solution. There are many advantages of using GA over traditional optimisation algorithms. For example, it is conceptually simple, and no gradient information is required. In addition, it can be used to adapt solutions to changing circumstances, therefore robust to dynamic changes in the environment. Furthermore, GA has the ability to deal with various optimisation problems including stationary or non-stationary, linear or non-linear, continuous or discontinuous objective functions [33-37]. GA is one of the earliest intelligent optimisation algorithms, and its convergence in the sense of probabilities has been widely used in practice. Matlab has a built-in function for GA, which is applicable to mixed integer nonlinear programming problems. In this work, the optimisation problem is to minimise the end user's energy cost, where the decision variables are the charging/discharging status of EV and ESS. Therefore, the problem can be expressed as a binary integer programming problem, and GA has been selected to find the solution.

\section{CASE STUDIES UNDER DIFFERENT SCENARIOS}

In this section, the optimisation problem in (26) is studied under different scenarios using two typical FITs.

\section{A. System Specifications}

Two tariffs are considered and used for comparison in the case studies; namely, the fixed flat tariff and the TOU tariff. The fixed tariff is $£ 0.152 / \mathrm{kWh}$, sourced from the First Utility Company. The 2014 TOU tariff is taken from Scottish and Southern Energy Public Limited Company. The peak time period is from 17:00 to 20:00, and the corresponding tariff is $£ 0.234 / \mathrm{kWh}$. The night time period is from 01:00 to 07:00, and the corresponding tariff is $£ 0.061 / \mathrm{kWh}$. The rest of the day is regarded as the off-peak time period and the tariff is $£ 0.117 / \mathrm{kWh}$. [38].

The Solar PV rating is less than $10 \mathrm{~kW}$, and the solar panel area for PV generation is selected to be $16 \mathrm{~m}^{2}$. Usually, the export tariff is regulated by the government, which is 5.03 pence/kWh in UK [32]. In addition, if the PV system is less than $10 \mathrm{~kW}$, the generation tariff is 3.93 pence/ $\mathrm{kWh}$ up to now [32]. Each EV's battery price in Table I is estimated through the data in [39], which equals approximately to $30 \%$ of the total projected price. The TESLA Powerwall is selected for the ESS battery storage. It has the capacity of $6.4 \mathrm{kWh}$ and the cost of $\$ 3,000$ (approximately $£ 2,300$ ) per pack. Also, the ESS capacity can be expanded through connection to multiple TESLA Powerwalls. The grid voltage supply to the considered residential house is $240 \mathrm{~V}$, and the charging/discharging current for EV and ESS are all 10A.

\begin{tabular}{lccccc}
\multicolumn{5}{c}{ TABLE I PRICE OF EV BATTERY PACKS } \\
\hline Brand & TESLA & TESLA & BMW I3 & SMART & LEAF \\
\hline $\begin{array}{l}\text { Capacity } \\
\text { (kWh) }\end{array}$ & 75 & 100 & 33 & 17.6 & 40 \\
$\begin{array}{l}\text { Projected } \\
\begin{array}{l}\text { EV Price } \\
(\mathfrak{f})\end{array}\end{array}$ & 64700 & 86200 & 34070 & 21465 & 21990 \\
$\begin{array}{l}\text { Battery } \\
\text { Price (£) }\end{array}$ & 19410 & 25860 & 10221 & 6440 & 6597 \\
\hline
\end{tabular}

The data for other residential loads, excluding EV and ESS, on a typical working day are also investigated in this case study, where there are two periods of higher demand at 6:00 am 10:00 am and 18:00 pm 22:00 pm sourced from the UK government report [40]. The Solar irradiance data are taken from [41], in which the selected month is January in the area of Glasgow, UK. 


\section{B. Numerical Studies under Different Minimum Terminal SOC Constraints and Initial SOC of EV}

In this case study, the initial displayed values of SOC in the ESS is fixed as $0 \%$. The selected EV model is BMW I3, for which the battery pack's price is approximately $£ 10,221$.

The operational cost minimisation problem in (26) is solved for different values of $S O C_{L B}^{E V}$ and initial SOC. Both of fixed tariff and TOU tariff are applied, and the minimal operation costs under different levels of $S O C_{L B}^{E V}$ are shown in Fig. 3 and Fig. 4, respectively. It can be seen that user's cost increases with the increase of $S O C_{L B}^{E V}$ provided that $S O C_{L B}^{E V}>S O C_{I N}^{E V}$ if $S O C_{I N}^{E V}$ is not changing. This is because the EV needs to be charged in order to ensure a higher remaining $\mathrm{SOC}$ at the end of the control period. If $S O C_{L B}^{E V}<S O C_{I N}^{E V}$, then the user's minimal operational cost stays at the same minimum value. The optimised results on $P_{2}(i)$ and $P_{3}(i)$ show that there is no discharging either from EV or from ESS when $S O C_{L B}^{E V}<S O C_{I N}^{E V}$, which means that there is no power sold back to the grid under this circumstances. This is because the value of the export tariff is too low, and the degradation cost of battery discharging cannot be compensated under such a low tariff. In addition, it can be observed that the operational cost under this particular TOU tariff is lower than that of the fixed tariff.

Furthermore, the results also suggest that the operational cost to charge the same amount of energy to the battery will increase when the initial SOC increases. For example, according to the results of the fixed tariff in Appendix Table D3, the optimal operational cost is $£ 4.91$ to charge the EV from $S O C_{I N}^{E V}=0$ to $S O C_{E V}=50 \%$; however, it can be seen from Table D1 in Appendix that a slightly higher cost of $£ 4.96$ is needed to charge the $\mathrm{EV}$ from $S O C_{I N}^{E V}=50 \%$ to $S O C_{E V}=100 \%$, although in both cases, charging of the battery requires the same amount of energy. The underlying reason can be understood from (8), where it shows that a lower initial SOC will lead to a lower battery degradation cost. For the TOU tariff, the results give a similar conclusion that the operational cost decreases with the increase of the initial SOC.

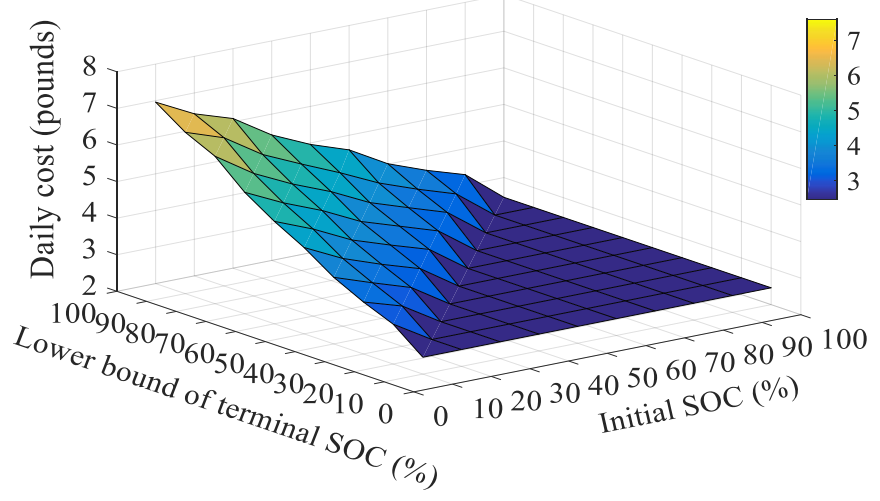

Fig. 3. Impact of different SOC constraints and initial SOC of EV under fixed tariff

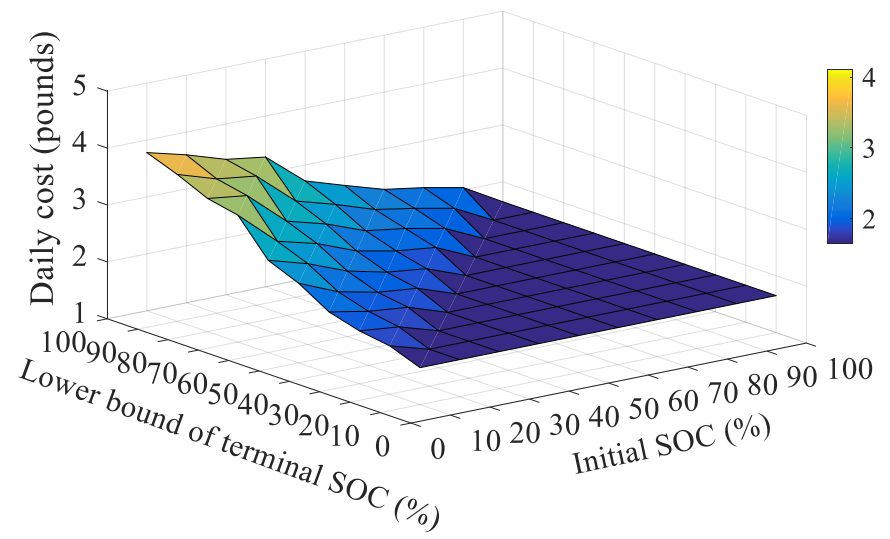

Fig. 4. Impact of different SOC constraints and initial SOC of EV under TOU tariff

\section{Impact of Different $v_{\text {export }}$ of Feed-in Tariffs}

The $v_{\text {export }}$ value of FIT will affect end users whether to participate in $\mathrm{V} 2 \mathrm{G}$ market or not. In the following simulation, the initial SOC values are set to be $100 \%$ for both EV and ESS (fully charged). The lower bound of terminal SOC is selected as $0 \%$ so as to check the maximum possible amount of energy discharged and obtain the minimum value of $v_{\text {export }}$ which makes V2G profitable. After comparing different EV charging/discharging results from the optimisation, it is found that EV will start to discharge power only if the export tariff is larger than the threshold value of $£ 0.25 / \mathrm{kWh}$ for the fixed tariff, and $£ 0.15 / \mathrm{kWh}$ for the TOU tariff. The simulation result shows that the export tariff has to be at least $£ 0.96 / \mathrm{kWh}$ in order to achieve a positive net income under a fixed tariff, and $£ 0.60 / \mathrm{kWh}$ under a TOU tariff. These results are shown in Fig. 5 for the fixed and the TOU tariffs, where a negative value of operational cost implies there is a positive net income. Fig. 6 shows the results of EV and ESS charging/discharging status for the TOU tariff, where ' +1 ' means discharging, ' -1 ' means charging, and ' 0 ' means no charging or discharging takes place.

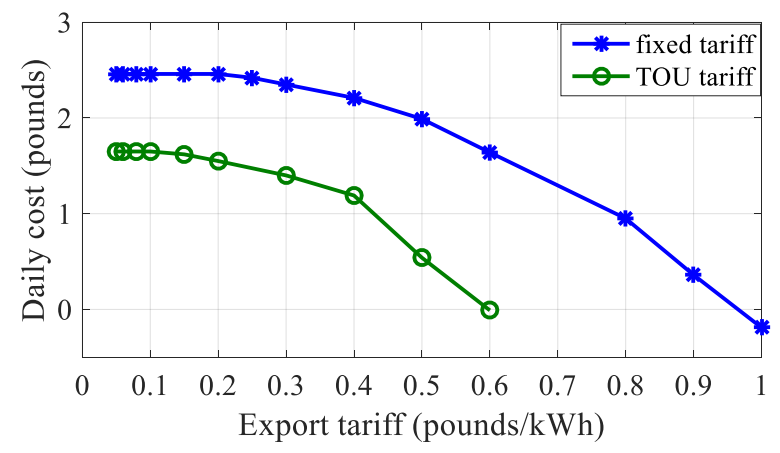

Fig. 5. Impact of $v_{\text {export }}$ of FIT to daily mini

It can be found from Fig. 6 that the EV discharging time is within the electricity consumption peak time period. This can help to shave the peak load for the end user, so it can be concluded that charging/discharging profiles of EV and ESS are influenced by the electricity tariff. In addition, the charging/discharging profiles of EV is also influenced by the probability of EV parking at home. According to the survey data, the probability of EV parking at home during night time 
is much higher than during the day time; therefore, the EV charging/discharging can be operated more often during the night time.
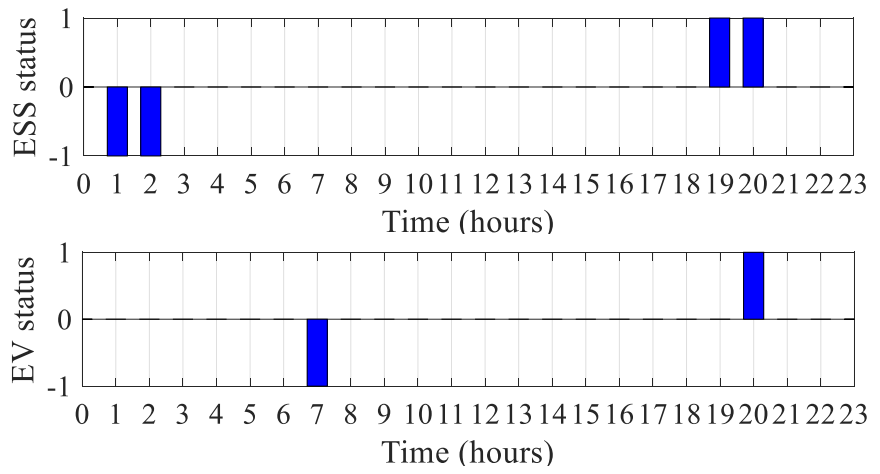

Fig. 6. EV and ESS charging/discharging profiles for TOU tariff

Compared with EV, such a parking-at-home probability factor is not applicable to ESS, so the electricity tariff is the only factor that influences the profile of ESS charging/discharging. When the electricity tariff is fixed, there are in general many random solutions for ESS satisfying all the constraints, including the SOC constraints. Therefore it is of less interest to discuss the fixed tariff situation. As can be seen from Fig. 6, ESS is charged during the off-peak time when the tariff is the lowest, and discharged during the peak-time when the tariff is the highest. This verifies that the results calculated through our model are reasonable for practical applications, and the optimisation solution is more efficient under the TOU tariff than that under the fixed tariff.

\section{Impacts of Different Probabilities of EV Plugging in at Home and Different PV Generation}

In this case, the initial SOC value is setting as $50 \%$ and the lower bound of the terminal SOC is $60 \%$. Therefore, no matter how the other factors are varied, such as load change characteristics, PV generation characteristics and so on, the EV must be charged at least $10 \%(60 \%-50 \%)$ in order to satisfy the constraint. To investigate the impacts of different probabilities of EV parking at home, three different values are applied, which are 50\%, 80\%, and the probability value calculated from the survey. The electricity tariff is selected as TOU, which is shown in Fig. 7.

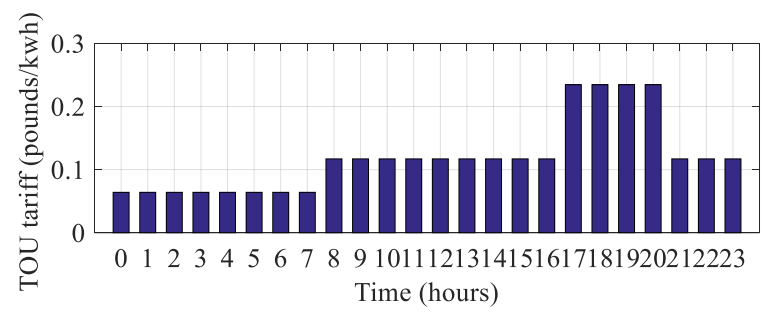

Fig. 7. TOU electricity tariff

Results of EV charging status and daily costs for different probabilities are shown in Fig. 8 and Table II, respectively. It can be seen from these results that EV is always charged during night time period with the TOU tariff regardless of the parking probabilities. This is because the night time tariff is the lowest during the 24 hours period. In addition, the results show that lower parking probabilities at home require more times of charging for the same amount of power to be charged, and this will lead to higher cost for the end user.

During the whole year, the solar radiation variations between each month will result in different outcomes of the optimisation. Results in Table III show the daily costs of PV power generation across the 12 months. It can be seen that the daily costs are decreased in the month with higher solar radiation. The end user can make profits between March and September when the optimisation strategy is applied.

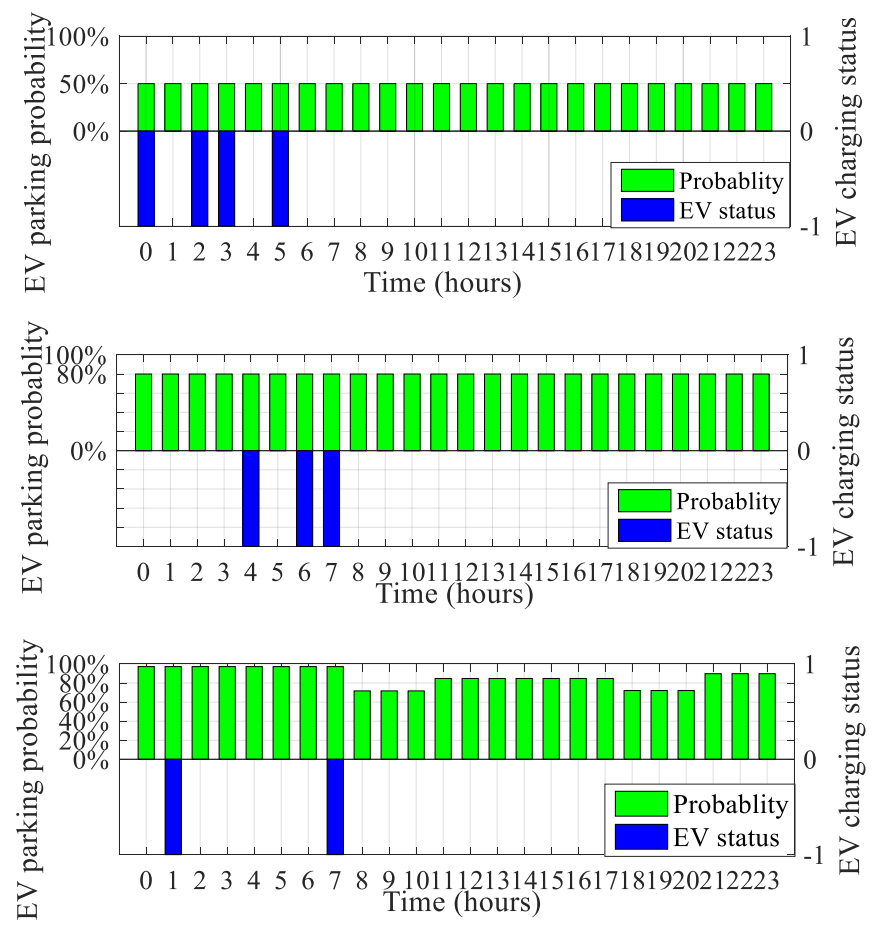

Fig. 8. EV charging/discharging profile for different plugging-in probabilities

TABLE II PRICE OF DIFFERENT PLUGGING-IN PROBABILITIES

\begin{tabular}{lcc}
\hline Probability of plugging-in & EV charging times & Total cost (£) \\
\hline $50 \%$ & 4 & 1.92 \\
$80 \%$ & 3 & 1.84 \\
Survey result & 2 & 1.78 \\
\hline
\end{tabular}

E. With and Without Considering Battery Degradation Cost

Now consider the scenario when the battery degradation cost is ignored in the operational cost minimisation, and compare it with the previous cases where the battery degradation cost is included. This comparison is made with a focus on the impact of different EV capacities under the TOU tariff. All the initial values are set to be the same as those in previous cases. The results are shown in Fig. 9, which can be observed that the daily cost of users is much lower when the battery degradation is ignored. However, this is not realistic because battery degradation always exists during charging and discharging processes. According to the results in subsection II D., the existing $v_{\text {export }}$ value cannot compensate the battery degradation cost for $\mathrm{V} 2 \mathrm{G}$ service; therefore, the optimisation 
TABLE III DAILY COSTS OF DIFFERENT MONTH

\begin{tabular}{cccccccccccccc}
\hline Month & Jan & Feb & Mar & Apr & May & Jun & Jul & Aug & Sep & Oct & Nov & Dec \\
\hline $\begin{array}{c}\text { After } \\
\text { optim. } \\
(\mathfrak{f})\end{array}$ & 1.65 & 0.63 & -0.38 & -1.21 & -1.49 & -1.34 & -1.22 & -0.95 & -0.56 & 1.03 & 1.60 & 1.59 \\
$\begin{array}{c}\text { Before } \\
\text { optim. } \\
(\mathfrak{(})\end{array}$ & 1.85 & 1.52 & 1.08 & 0.46 & 0.11 & 0.21 & 0.37 & 0.73 & 1.04 & 1.50 & 1.69 & 1.97 \\
\hline
\end{tabular}

without considering battery degradation cost is not feasible for the benefit of the end user.

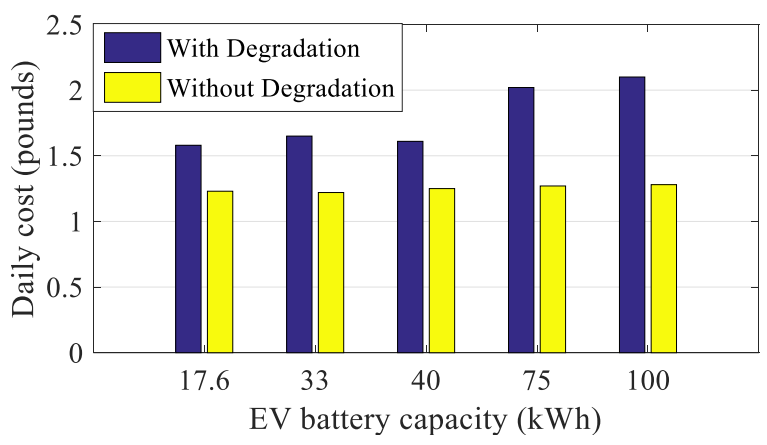

$$
\begin{gathered}
C_{\text {total }}^{\text {non-opt }}=\sum_{i=1}^{24} P_{5}(i) \cdot\left[\operatorname{sgn}\left(P_{5}(i)\right) \cdot \mu(i)-\left(\operatorname{sgn}\left(P_{5}(i)\right)-1\right) \cdot v_{\text {export }}(i)\right] \\
-\sum_{i=1}^{24} P_{1}(i) \cdot v_{\text {generation }}(i)+C_{E V-\text { driving }}+C_{E V \text {-average }}
\end{gathered}
$$

The total daily cost without optimisation is much higher than the optimised cost calculated through our model, as compared in Table IV. The results show that the cost saving after optimisation is dependent on the EV models, and the highest cost saving is found to be $15 \%$ in this study for TESLA Model S 100D.

TABLE IV

Fig. 9. Impact of battery degradation to daily minimal operational cost

\section{F. Comparison with Non-optimised Strategy}

In this section, the residential household user's daily cost under existing non-optimised operational schedule is compared with the optimised cost. ESS is not considered here as it is not popular in most of the non-optimised residential uses. The EV charging cost, $C_{E V \text {-driving }}$, depends on how much electricity power is charged to the battery, while the charging amount can be represented by the amount of SOC charged. In addition, the expected charging amount of SOCs for different EVs in order to fulfil the tentative daily driving distance can be represented as $\sum_{l=1}^{N_{d}} d(l) p_{l} / d_{\text {total }}$; therefore, the daily driving costs can be expressed as:

$$
C_{E V-\text { driving }}=\mu \cdot \sum_{l=1}^{N_{d}} \frac{d(l) p_{l}}{d_{\text {total }}}
$$

Furthermore, the battery degradation cost needs to be added into the total cost. The average daily battery degradation cost, $C_{E V \text {-average }}$, is calculated by (21). The overall non-optimised daily cost is calculated by (28), which is also the baseline for cost reduction analysis.

\begin{tabular}{|c|c|c|c|c|c|c|c|}
\hline EV models & After optim. (£) & $\begin{array}{l}\text { Non-optim. } \\
\text { Peak time } \\
\text { charging }(£)\end{array}$ & Cost reduct. & $\begin{array}{l}\text { Non-optim. Off- } \\
\text { peak time } \\
\text { charging }(£)\end{array}$ & Cost reduct. & $\begin{array}{l}\text { Non-optim. } \\
\text { night time } \\
\text { charging (£) }\end{array}$ & Cost reduct. \\
\hline SMART & 1.58 & 2.88 & $45 \%$ & 2.23 & $29 \%$ & 1.93 & $18 \%$ \\
\hline BMW I3 & 1.65 & 2.87 & $42 \%$ & 2.28 & $27 \%$ & 2.01 & $18 \%$ \\
\hline LEAF & 1.61 & 3.10 & $48 \%$ & 2.34 & $31 \%$ & 1.99 & $19 \%$ \\
\hline TESLA(75) & 2.02 & 3.60 & $44 \%$ & 2.84 & $29 \%$ & 2.50 & $19 \%$ \\
\hline TESLA(100) & 2.10 & 3.75 & $44 \%$ & 2.95 & $29 \%$ & 2.59 & $19 \%$ \\
\hline
\end{tabular}

TABLE V

TOTAL DAILY COST COMPARISON (TOU TARIFF) 
TABLE VI COMPARISON OF CHARGING/DISCHARGING/DEGRADATION COST IMPACTS BEFORE AND AFTER OPTIMISATION

\begin{tabular}{|c|c|c|c|}
\hline Cost impacts & After optimisation & $\mathrm{Be}$ & e optimisation \\
\hline $\begin{array}{l}\text { EV } \\
\text { charging/discharging }\end{array}$ & $\begin{array}{l}\text { For fixed tariff, EV is charged when the parking probability is high, which will } \\
\text { lead to lower cost. } \\
\text { For a TOU tariff, EV is charged when the tariff is lowest; and EV has higher } \\
\text { probabilities of charging when the probabilities of parking at home is higher. } \\
\text { V2G could happen with high FIT }\end{array}$ & • & $\begin{array}{l}\text { EV charging happens randomly } \\
\text { throughout } 24 \text { hours no matter which } \\
\text { tariffs are applied. } \\
\text { NO V2G function even when FIT is high } \\
\text { enough to compensate the degradation } \\
\text { cost. }\end{array}$ \\
\hline EV degradation & $\begin{array}{l}\text { Depends on the optimisation solution. For example, if more discharging } \\
\text { happens with higher FIT, the degradation cost will be higher. However, the } \\
\text { total cost will be reduced. If FIT is unchanged, the degradation cost will be } \\
\text { similar to the value before optimisation. }\end{array}$ & $\bullet$ & $\begin{array}{l}\text { Mainly results from the amount of SOC } \\
\text { charged/discharged and daily driving } \\
\text { distance. }\end{array}$ \\
\hline $\begin{array}{l}\text { ESS } \\
\text { charging/discharging }\end{array}$ & $\begin{array}{l}\text { For fixed tariff, ESS will be charged/discharged randomly. } \\
\text { For TOU tariff, ESS will be charged when the tariff is the lowest, and } \\
\text { discharged when the tariff is high. } \\
\text { Power selling back to grid could happen with high FIT. }\end{array}$ & $\bullet$ & $\begin{array}{l}\text { EV charging happens randomly } \\
\text { throughout } 24 \text { hours no matter which } \\
\text { tariffs are applied. } \\
\text { NO power selling back to grid }\end{array}$ \\
\hline ESS degradation & Similar to EV degradation & • & $\begin{array}{l}\text { Mainly results from the amount of SOC } \\
\text { charged/discharged and the discharging } \\
\text { time periods throughout a day. }\end{array}$ \\
\hline
\end{tabular}

\section{G. Home Energy System Model involving Solar Water Heater}

To explore further of the proposed cost optimisation problem with added complexity, an additional controllable load, which is a solar water heater, has been added. Let $P_{e}$ be the power of the electric back-up element of the solar water heater that can be expressed as:

$$
P_{e}(i)= \begin{cases}-\kappa, & \text { if water needs to be heated } \\ 0, & \text { otherwise }\end{cases}
$$

In order to satisfy the hot water demand throughout the day, the hot water temperature in the storage tank should be maintained to certain range. The constraint of the hot water temperature in the storage tank can be written as:

$$
\left|T_{s}(i)-T_{\text {expected }}(i)\right| \leq Z
$$

where $Z$ is the acceptable fluctuation range of the temperature within time period $i ; T_{\text {expected }}(i)$ is the expected hot water's temperature and $T_{s}(i)$ is the actual hot water temperature of the tank. Taking all the above factors into account, an optimisation problem is formulated to minimise the expectation of the total operating cost of the residential home energy system, where $f$ is a dynamic function calculating the contribution of electric power to water temperature [42].

$$
\begin{aligned}
& \min C_{\text {total }}\left(P_{2}(i), P_{3}(i), P_{e}(i)\right) \\
& \text { subject to: } S O C_{\text {min }}^{E V} \leq S O C_{E V}(i) \leq S O C_{\text {max }}^{E V} \\
& S O C_{\min }^{E S S} \leq S O C_{E S S}(i) \leq S O C_{\max }^{E S S} \\
& S_{S O C_{E V}}(24) \geq S O C_{L B}^{E V} \\
& \sum_{j=1}^{5} P_{j}(i)+P_{e}(i)=0 \\
& T_{s}(i+1)-T_{s}(i)=g\left(P_{e}(i)\right) \\
& \left|T_{s}(i)-T_{\text {expected }}(i)\right| \leq Z
\end{aligned}
$$

The comparison of the results between the optimised and the non-optimised solutions has been investigated. The selected EV is the Tesla Model S 100D, the electricity tariff is fixed, and the hot water consumption has been included in the load curve [40]. The comparison between the optimised and non-optimised total

\begin{tabular}{|c|c|c|c|}
\hline $\begin{array}{l}\text { Storage } \\
\text { Volume } \\
\text { (L) }\end{array}$ & $\begin{array}{l}\text { Total cost } \\
\text { without } \\
\text { optimisation } \\
\text { (£) }\end{array}$ & $\begin{array}{l}\text { Total cost } \\
\text { after } \\
\text { optimisation } \\
\text { (f) }\end{array}$ & Cost reduction (\%) \\
\hline 80 & 3.19 & 2.67 & $16 \%$ \\
\hline 120 & 3.19 & 2.61 & $18 \%$ \\
\hline 160 & 3.19 & 2.55 & $20 \%$ \\
\hline 200 & 3.19 & 2.43 & $24 \%$ \\
\hline 240 & 3.19 & 2.36 & $26 \%$ \\
\hline
\end{tabular}
household energy costs under different storage volumes of solar water heaters is shown in Table VII, from which it can be seen that the cost of user can be effectively reduced at least $16 \%$ even though the selected month is January, arguably the most cold time during the year. In addition, if a larger volume of the solar heater storage is applied, a larger amount of energy will be stored for load shifting purpose, and the daily cost can be further reduced.

\section{H. Payback Period (PB) Analysis for Different Scenarios}

Three different types of household are compared, which are traditional household, smart household with PV, and smart household without PV. In addition, impacts of different capacities of ESS are obtained. Discussions and analysis of these different scenarios are presented from the perspective of return on investment.

A traditional household usually has no self-power supply equipment, such as PV and small wind turbine, and its electricity power is usually provided by external power grid. In addition, the end users of traditional household may also use electricity for cooking or heating, and the vehicles they selected are usually combustion vehicles; therefore, the energy consumption for the end user could be divided into two parts for a traditional household: electricity consumption and petrol/diesel consumption due to car driving. The total energy cost for a traditional household is calculated from

$$
C_{\text {traditional-driving }}+C_{\text {electricity }}=C_{\text {total }}
$$

The end user's daily cost of the electricity consumption can be calculated as follows:

$$
C_{\text {electricity }}=\sum_{i=1}^{24} P_{\text {load }}(i) \cdot \mu(i)
$$


where $P_{\text {load }}(i)$ is hourly electricity consumption during the $i$ th period; $\mu(i)$ is the electricity tariff during time $i$ period; Following the data provided from Section III. A, the daily cost of electricity consumption can be obtained via (33), which is $£ 1.99$ tariff. The annual cost of electricity consumption, $C_{e}$, is calculated through the daily costs multiplied by a factor of 365 , which is $£ 726.35$ under the fixed tariff.

The annual expected cost of $C_{\text {traditional-driving }}$ is obtained from Appendix Table D5, which is $£ 1,746$. Therefore, the total energy cost for a household is $£ 2,472(£ 1,746+£ 726.35)$.

The daily costs of the electricity consumption under fixed tariff after optimisation can be calculated for both of PV included system and non-PV system, the annual cost savings compared to the traditional household can be obtained as shown in Table VIII. Then, the payback periods between these two systems are shown in Table IX.

From Table IX, it can be seen that if the system does not include PV generation, the payback periods are much shorter, which means the end user will spend less time to get back the initial investment. The majority of manufactures offer the 25year standard solar panel warranty, the PV lifespan can be selected as 25 years. If the longer-term profits of the return on investment are considered, such as 10 years or 20 years, the profits will be much higher if PV system is included according to the cost savings from Table VIII. Therefore, PV generation system is recommended in our optimisation model.

Furthermore, the daily costs will not be influenced by the number of PowerWalls after optimisation. This is mainly because the unit price of the PowerWall $(£ / \mathrm{kWh})$ is not changed. However, if the end user installs more PowerWalls, the initial investment will be much higher, which leads to longer payback period of the whole system. Therefore, multiPowerwalls are not recommended for the end user.

\begin{tabular}{cccccc}
\multicolumn{6}{c}{ TABLE VIII COST SAVINGS WITH PV AND WITHOUT PV } \\
\hline EV & $\begin{array}{c}\text { BMW } \\
\text { I3 }\end{array}$ & SMART & LEAF & $\begin{array}{c}\text { Tesla } \\
75\end{array}$ & $\begin{array}{c}\text { Tesla } \\
100\end{array}$ \\
\hline $\begin{array}{c}\text { Cost savings with } \\
\text { PV (£) }\end{array}$ & 2140 & 2163 & 2153 & 2002 & 1978 \\
$\begin{array}{c}\text { Cost savings Non- } \\
\text { PV(£) }\end{array}$ & 1421 & 1444 & 1434 & 1283 & 1259 \\
\hline
\end{tabular}

\begin{tabular}{cccccc}
\multicolumn{5}{c}{ TABLE IX PB COMPARISON FOR DIFFERENT EVS } \\
\hline EV & $\begin{array}{c}\text { BMW I3 } \\
\text { (years) }\end{array}$ & $\begin{array}{c}\text { SMART } \\
\text { (years) }\end{array}$ & $\begin{array}{c}\text { LEAF } \\
\text { (years) }\end{array}$ & $\begin{array}{c}\text { Tesla 75 } \\
\text { (years) }\end{array}$ & $\begin{array}{c}\text { Tesla 100 } \\
\text { (years) }\end{array}$ \\
\hline PB with & 4.7 & 4.7 & 4.7 & 5.1 & 5.1 \\
PV (£) & & & & & \\
PB Non- & 2.9 & 2.9 & 2.9 & 3.2 & 3.3 \\
PV(£) & & & & & \\
\hline
\end{tabular}

\section{CONCLUSIONS}

In this paper, an operational cost minimisation model is developed for a residential energy system comprising of an EV, an ESS, a PV system and other residential loads. To address the challenges of uncertain customer driving patterns, the probabilities of different driving time periods are obtained through a set of survey data. The survey was developed to cover various factors including driving purposes, driving time periods and distance, and also EV parking time. The design objective is to minimise the expected overall cost of the residential energy system on daily basis under uncertain car usage.

In the case studies, impacts of the initial and the terminal SOC values are tested, where the results show that the total operational cost remains at the same minimum value if the initial SOC value is larger than or equal to the lower bound of the terminal SOC. This is because the existing $v_{\text {export }}$ is not large enough to compensate for the degradation cost of battery's discharging, and thus, there is no power return either from ESS to home supply or from EV through V2G. Also, the overall cost measure will increase when the initial SOC is smaller than the lower bound of the terminal SOC. The overall cost for the end user will be slightly smaller if charging the same amount of energy to EV from a lower initial SOC. Several EV models are considered, and the economical choice has been provided. In addition, different impacts of $v_{\text {export }}$ of FIT are discussed. The results show that the EV will only start to discharge when the $v_{\text {export }}$ is larger than or equal to $£ 0.25 / \mathrm{kWh}$ for fixed tariff, and $£ 0.15 / \mathrm{kWh}$ for TOU tariff in the case study.

It can be concluded that V2G can only be profitable to end users when $v_{\text {export }}$ is larger than a certain threshold. This threshold could be decreased if the battery degradation cost is reduced in the future. Furthermore, a comparison is made with the non-optimised operation and other scenarios. It shows that the proposed optimisation can achieve cost savings from $9 \%$ to $15 \%$ under the selected fixed tariff, and from $18 \%$ to $48 \%$ under the given TOU tariff. Finally, an additional controllable load, solar water heater, is added in the optimisation model for exploration of wider applications.

The investigation in this work is based on survey data collected on daily basis, and the optimisation is therefore of static nature. One expansion of this study is to develop online operation control for similar systems. A practical implementation procedure of the optimised operational schedules will be developed, and a prediction of customer's benefit of $\mathrm{V} 2 \mathrm{G}$ with future battery price will also be investigated.

\section{REFERENCES}

[1] A. Foley, B. Tyther, P. Canlnan, and B. Gallachóir, "Impacts of electric vehicle charging under electricity marktet operations," Appl Energy, vol. 101, pp. 93-102, Jan. 2013.

[2] J. Tang, B. Ye, Q. Lu, D. Wang, and J. Li, "Economic analysis of photovoltaic electricity supply for an electric vehicle fleet in shenzhen, china," Int J Sustain Transp, vol. 8, pp. 202-224, Feb. 2014.

[3] M. A. Ortega-Vazquez, "Optimal scheduling of electric vehicle charging and vehicle-to-grid services at household level including battery degradation and price uncertainty," IET Gener Transm Dis, vol. 8, pp. 1007-1016, Nov. 2013.

[4] Y. Cao, S. Tang, C. Li, P. Zhang, Y. Tan, Z. Zhang, et al., "An optimized EV charging model considering TOU Price and SOC curve," IEEE Trans Smart Grid, vol. 3, pp. 388-393, 2012.

[5] G. Carpinelli, F. Mottola, and D. Proto, "Optimal scheduling of a microgrid with demand response resources," IET Gener Transm Dis, vol. 8, pp. 1891-1899, Dec. 2014.

[6] C.-T. Li, C. Ahn, H. Peng, and J. Sun, "Synergistic control of plug-in vehicle charging and wind power scheduling," IEEE Trans Power Syst, vol. 28, pp. 1113-1121, Sep. 2012.

[7] W. Tushar, C. Yuen, S. Huang, D. B. Smith, and H. V. Poor, "Cost minimization of charging stations with photovoltaics: a approach with 
EV classification," IEEE Trans Intell Transp Syst, vol. 17, pp. 156169, Jan. 2016

[8] H. Liu, Z. Hu, Y. Song, and J. Lin, "Decentralized vehicle-to-grid control for primary frequency regulation considering charging demands," IEEE Trans Power Syst, vol. 28, pp. 3480-3489, 2013.

[9] T. Masuta and A. Yokoyama, "Supplementary load frequency control by use of a number of both electric vehicles and heat pump water heaters," IEEE Trans Smart Grid, vol. 3, pp. 1253-1262, 2012.

[10] S. Rezaee, E. Farjah, and B. Khorramdel, "Probabilistic analysis of plug-In electric vehicles impact on electrical grid through homes and parking lots," IEEE Trans Sustain Energy, vol. 4, pp. 1024-1033, Sep. 2013.

[11] L. Jian, Y. Zheng, X. Xiao, and C. C. Chan, "Optimal scheduling for vehicle-to-grid operation with stochastic connection of plug-in electric vehicles to smart grid," Appl Energy, vol. 146, pp. 150-161, 2015.

[12] P. Richardson, D. Flynn, and A. Keane, "Optimal charging of electric vehicles in low-voltage distribution System," IEEE Trans Power Syst, vol. 27, pp. 268-279, Feb. 2012.

[13] L. Drude, L. C. P. Junior, and R. Rüther, "Photovoltaics (PV) and electric vehicle-to-grid (V2G) strategies for peak demand reduction in urban regions in Brazil in a smart grid environment," Renew Sust Energ Rev, vol. 68, pp. 443-451, 2014.

[14] A. Rabiee, M. Sadeghi, J. Aghaeic, and A. Heidari, "Optimal operation of microgrids through simultaneous scheduling of electrical vehicles and responsive loads considering wind and PV units uncertainties," Renew Sust Energ Rev, vol. 57, pp. 721-739, 2016.

[15] M. v. d. Kam and W. v. Sark, "Smart charging of electric vehicles with photovoltaic power and vehicle-to-grid technology in a microgrid; a case study," Appl Energy, vol. 152, pp. 20-30, 2015.

[16] G. R. Parsons, M. K. Hidrue, W. Kempton, and M. P. Gardner, "Willingness to pay for vehicle-to-grid (V2G) electric vehicles and their contract terms," Energy Econ, vol. 42, pp. 313-324, Jan. 2014.

[17] D. B. Richardson, "Encouraging vehicle-to-grid (V2G) participation through premium tariff rates," J Power Sources, vol. 243, pp. 219-224, Jun. 2013.

[18] J. D. K. Bishop, C. J. Axon, D. Bonilla, M. Tran, D. Banister, and M. D. McCulloch, "Evaluating the impact of V2G services on the degradation of batteries in PHEV and EV," Appl Energy, vol. 111, pp. 206-218, May 2013.

[19] X. Hu, C. M. Martinez, and Y. Yang, "Charging, power management, and battery degradation mitigation in plug-in hybrid electric vehicles: A unified cost-optimal approach," Mech Syst Signal Process, vol. 87, pp. 4-16, 2017.

[20] O. Erdinc, N. G. Paterakis, T. D. P. Mendes, A. G. Bakirtzis, and J. P. S. Catalão, "Smart household operation considering bi-directional EV and ESS utilization by real-time pricing-based DR," IEEE Trans Smart Grid, vol. 6, pp. 1281-1291, 2015.

[21] H. Farzin, M. Fotuhi-Firuzabad, and M. Moeini-Aghtaie, "A practical scheme to involve degradation cost of lithium-ion batteries in vehicleto-grid applications," IEEE Trans Sustain Energy, vol. 7, pp. 1730$1738,2016$.

[22] L. Igualada, C. Corchero, M. Cruz-Zambrano, and F.-J. Heredia, "Optimal energy management for a residential microgrid including a vehicle-to-grid system," IEEE Trans Smart Grid, vol. 5, pp. 21632172, 2014.

[23] Q. Zhong, S. Buckley, A. Vassallo, and Y. Sun, "Energy cost minimization through optimization of $\mathrm{EV}$, home and workplace battery storage," Sci China Tech Sci, vol. 61, pp. 1-13, 2018.

[24] C. Zhou, K. Qian, M. Allan, and W. Zhou, "Modeling of the cost of EV battery wear due to V2G application in power systems," IEEE Transactions on Energy Conversion, vol. 26, pp. 1041-1050, 2011.

[25] R. Sharifia, S. H. Fathia, and V. Vahidinasabb, "A review on demandside tools in electricity market," Renew Sust Energ Rev, vol. 72, pp. 565-572, Jan. 2017.

[26] How to calculate the annual solar energy output of a photovoltaic system? Available: https://photovoltaic-software.com/PV-solarenergy-calculation.php

[27] Tesla. (2018). Powerwall. Available: https://www.tesla.com/sites/default/files/pdfs/powerwall/Powerwall $\% 202$ AC_Datasheet_en_northamerica.pdf

[28] A. Hoke, A. Brissette, K. Smith, A. Pratt, and D. Maksimovic, "Accounting for lithium-ion battery degradation in electric vehicle charging optimization," IEEE J Emerg Sel Top Power Electron, vol. 2, pp. 691-700, Sep. 2014

[29] A. Hoke, A. Brissette, K. Smith, A. Pratt, and D. Maksimovic, "Electric vehicle charge optimization including effects of lithium-ion battery degradation," presented at the IEEE VPPC Chicago, USA, 2011.

[30] Y. Zhang, C. Zhang, and X. Zhang, "State-of-charge estimation of the lithium-ion battery system with time-varying parameter for hybrid electric vehicles," IET Control Theory Appl, vol. 8, pp. 160-167, Feb. 2014.

[31] F. Martela, S. Kelouwanib, Y. Dubéb, and K. Agbossou, "Optimal economy-based battery degradation management dynamics for fuelcell plug-in hybrid electric vehicles," J Power Sources, vol. 274, pp. 367-381, Jan. 2015.

[32] ofgem. (2018). Feed-in-tariff (FIT) rates. Available: https://www.ofgem.gov.uk/environmental-programmes/fit/fit-tariffrates

[33] G. Lindfield and J. Penny, Introduction to Nature-Inspired Optimization: Elsevier, 2017.

[34] J. H. Holland, Adaptation in natural and artificial systems. USA: University of Michigan Press, 1975.

[35] X.-s. Yang, Nature inspired optimization algorithms. USA: Elsevier, 2014.

[36] R. Rojas, Neural Networks: A systematic introduction: Springer, 1996.

[37] D. B. Fogel, "The advantages of evolutionary computation," Proc of Bio-Computing and Emergent Comp, pp. 1-11, 1997.

[38] A. Chan, J. G. Moreno, and M. Hughes, "Further analysis of data from the household electricity study: electricity price signals and demand response," UK2014.

[39] Zach. (2014). Price of a nissan LEAF battery replacement $=£ 4,920$ in UK. evobesession. Available: http://evobsession.com/price-of-anissan-leaf-battery-replacement-4920-in-uk/

[40] J.-P. Zimmermann, M. Evans, J. Griggs, N. King, L. Harding, and P. Roberts, "Housedhold electricity survey: a study of domestic electrical product usage," Intertek Ltd, UK, 2012.

[41] (2017). Photovoltaic geographical information system. Available: http://re.jrc.ec.europa.eu/pvgis/apps4/pvest.php

[42] J. Zhang and X. Xia, "Best switching time of hot water cylinderswiched optimal control approach," presented at the IEEE AFRICON 2007, Windhoek, Namibia.

Yanyi Sun received BEng in Electronic and Electrical Engineering in 2012, from Northeast Electric Power University, Jilin, China, and MSc degree in Electronic and Electrical Engineering in 2014 from University of Strathlyde, UK. He is now a PhD student at the Department of Electronic and Electrical Engineering, University of Strathclyde. His research topic is on the application of demand side management in power systems.

Hong Yue (M'99, S'04) received BEng and MSc degrees in Industrial Process Control Engineering from Beijing University of Chemical Technology in 1990 and 1993, respectively, and the $\mathrm{PhD}$ degree in Control Theory and Applications from East China University of Science and Technology in 1996. She is a Senior Lecturer at the Department of Electronic and Electrical Engineering, University of Strathclyde. Her research interests are focused on dynamic systems modelling, model-based system analysis, optimal and robust experimental design, and advanced controller design for complex systems.

Jiangfeng Zhang received $\mathrm{BSc}$ degree and $\mathrm{PhD}$ degree in Computing Mathematics, in 1995 and 1999, respectively, from Xi'an Jiaotong University, Xi'an, China. He is currently a Senior Lecturer at the School of Electrical and Data Engineering, University of Technology Sydney. He is an associate editor for IET Renewable Power Generation, and also a Member of the IFAC TC6.3 (Power and Energy Systems). His research interests include smart grid and renewable energy

Campbell Booth received the B.Eng. and Ph.D. degrees in electrical and electronic engineering from the University of Strathclyde, Glasgow, UK in 1991 and 1996, respectively. He is currently a Professor and Head of Department for Electronic and Electrical Engineering, University of Strathclyde. His research interests include power system protection; plant condition monitoring and intelligent asset management; applications of intelligent system techniques to power system monitoring, protection, and control; knowledge management; and decision support systems 